\title{
Legitimacy of Authority and Protest Actions in Response to Collective Disadvantages
}

\author{
Jérôme Blondé ${ }^{1,2}$ (D) Vincenzo lacoviello ${ }^{1}$ - Dimitrios Lampropoulos ${ }^{2}$. \\ Matthieu Vétois ${ }^{1}$. Juan Manuel Falomir Pichastor ${ }^{1}$
}

Accepted: 7 July 2021 / Published online: 23 July 2021

(c) The Author(s) 2021

\begin{abstract}
A wealth of evidence has demonstrated that individuals' participation in collective actions largely derives from perceived group disadvantages. In the present research, we hypothesized that engagement in protest activities can be attenuated if the disadvantages originate from legitimate figures of authority. Across three experiments based on vignettes describing a hypothetical work setting (total $N=670$ ), we found consistent support for this prediction. In Study 1, we showed that intention to participate in a protest movement in reaction to an unfavourable distribution of outcomes was lower when legitimacy of the group's authority was high (vs. low). In addition, a reduction in anger was found to play a mediating role. Studies 2 and 3 further demonstrated that these effects only occurred when participants were confronted with a relatively low disadvantage (as opposed to a high disadvantage). In an attempt to identify underlying mechanisms, Study 3 emphasized the moral implications that lie behind responses to high (vs. low) disadvantageous decisions and that shape resistance processes. Taken together, these findings call for more consideration for the role of group authorities in the comprehension of collective action tendencies and give insights to better understand how and when authority legitimacy can serve to perpetuate social disparities and hinders the fight against injustices.
\end{abstract}

Keywords Authority legitimacy · Collective actions · Disadvantage · Anger · Violation of moral values

Jérôme Blondé

Jerome.blonde@unige.ch

1 University of Geneva, Boulevard du Pont D’Arve, 40, 1211 Geneva, Switzerland

2 University of Lausanne, Lausanne, Switzerland 


\section{Introduction}

In response to the introduction of restrictive socio-economic policies and unpopular reforms, the number of massive protest movements around the world has risen dramatically in recent years (Ancelovici et al., 2016; Della Porta \& Mattoni, 2014). The cases of the Indignados movement in Spain, the Occupy Wall Street movement in the USA or, more recently, the Gilet Jaunes movement in France are examples amid others. Notwithstanding the claims and grievances raised by the protesters are manifold and often disparate, it seems that a shared sense of being disadvantaged by an unequal distribution of wealth among citizens has unanimously fuelled such a surge of political activism. As an illustration, the Declaration of the Occupation of New York City was presented as follows: "As we gather together in solidarity to express a feeling of mass injustice, we must not lose sight of what brought us together" (Occupy Wall Street, 2011). In parallel, the mutualization of opposition forces and close cooperation between social actors in establishing collective protest movements (e.g. political marches, strikes, petitions) still remains a preferred modus operandi to redress for the disadvantages resulting from an unequal system and restore justice of the social order.

Likewise, research in social psychology has largely acknowledged that the perception that one's group suffers from structural injustice or disadvantages plays a crucial role in individuals' support and participation in collective actions (Klandermans, 1997; Wright, 2001; Wright et al., 1990). In the present work, we aimed to expand this research by investigating the effects of collective disadvantages on intention to engage in protest actions as a function of authority legitimacy.

\section{Collective Disadvantages and Participation in Collective Actions}

By the late 1960s, the relative deprivation theory (RTD) posited collective consciousness of being unfairly deprived of benefits or provided with burdens as a prerequisite for individuals' engagement in protest movements. Collective actions were theorized to build on the perception that one's group suffer from more disadvantages relative to other similar groups (Runciman, 1966; Smith \& Ortiz, 2002). Since then, a myriad of studies has provided convergent support for this view and the importance of perceived injustice in sparking collective actions has been reflected in a great number of social psychological models (Becker \& Tausch, 2015; Van Stekelenburg \& Klandermans, 2013; Van Zomeren et al., 2008, 2018; Wright, 2010). Perhaps most notably, this is the case with one of the most influential theoretical models to date, the social identity model of collective action (SIMCA; van Zomeren et al., 2004, 2008), which elevates perceived injustice as one of the few key precursors of collective actions. Along with group efficacy (i.e. the extent to which protest actions are viewed to be effective for redress of grievances) and identification (i.e. the extent to which protest group has a particular subjective importance), this model proposes that individuals take part in 
collective actions to the extent that their group is perceived to deal with blatant inequalities. Similarly, in their review of the collective action literature, Becker and Tausch (2015) illuminated the pivotal role of injustice appraisals, in addition to efficacy appraisals, in fuelling motivation to engage in a protest movement. Accordingly, perceived group disadvantages lie at the very heart of the concerns leading individuals to participate in collective actions.

Research surrounding the RDT has highlighted that group-based injustice encompasses cognitive and affective components, which both play a role in mobilizing people into collective actions (see Walker \& Smith, 2002). Perceived disadvantage constitutes the cognitive dimension of injustice, whereas group-based emotions, such as anger or resent, form the affective dimension. Against this backdrop, a wide range of studies have shown that perceived group disadvantages propel participation in collective actions through anger (e.g. Becker \& Tausch, 2015; Leach et al., 2007; Thomas et al., 2009; Van Zomeren et al, 2004, 2008; Yzerbyt et al., 2003). Based on the intergroup emotion theory (Mackie et al., 2000), the perception of being treated unfairly has been theorized as eliciting emotional reactions of anger, which in turn trigger action tendencies to resist and oppose those responsible for the wrongs committed.

However, despite a high sense of disadvantage, individuals may not necessarily invest much effort into initiating or taking part in collective actions. It has been shown that socio-economic inequalities and structural status-based differences between social groups may be well accepted by those most negatively affected and may provoke relatively little opposition (Becker et al., 2017; Jost et al., 2012, 2017). In the same vein, the present research focused on the role of group authorities and aimed to show that the perceived legitimacy of authority figures is capable of mitigating the readiness to participate in protest movements in response to an unfair treatment. ${ }^{1}$

\section{Legitimacy of Authority Figures and Compliance}

Legitimacy of authority may be defined as the perception that authority figures, such as CEOs, managers, or group leaders, are appropriately entitled to exercise their power and status within a given community (Tyler, 2006a). An authority derives its legitimacy, in part, from alignment with social norms, values, or practices that are commonly shared within the group (Zelditch, 2001), or from respect with the rules of procedural justice, such as neutrality or representativeness (e.g. Sunshine \& Tyler, 2003; Tyler \& Lind, 1992; Tyler, 2006a, 2010).

\footnotetext{
1 Throughout this manuscript, we consider injustice (or, more broadly, disadvantage) in reference to the dimension of distributive justice, which corresponds to what one person or group receives from a given distribution in relation to others or in relation to other groups. This dimension has largely been privileged in conceptualizations and operationalizations of perceived injustice in socio-psychological research on collective actions, particularly those developed around the RTD (see Van Stekelenburg \& Klandermans, 2013). In parallel, procedural justice refers to the justice of formal policies surrounding outcome distribution and how authorities make decisions and treat group members (Blader \& Tyler, 2003).
} 
Perception of legitimacy is vital for the group functioning and has profound consequences for cooperation between group members and authority (Tyler, 1997, 2006a). As a fundamental collective belief (Johnson et al., 2006), legitimacy establishes an implicit social contract giving authority the right to impose decisions and obliging subordinates to comply with them, regardless of punishments or rewards that they may receive (Zelditch \& Walker, 2003). In this sense, legitimacy creates a sense of obligation and deference to authority and justifies group members' consent to its decisions (Tyler, 2006b).

A wide array of work has shown that individuals tend to be more compliant with decisions made by authorities that are perceived legitimate (e.g. Hegtvedt \& Johnson, 2009; Levi et al., 2009; Tyler \& Huo, 2002; Tyler, 2006a). For example, cooperation with legal authorities, acceptance of judicial sentences, obedience to the law, and compliance with tax payments have been found to be stronger to the extent that they are viewed as legitimate (e.g. Jackson et al., 2012; Murphy et al., 2009; Tyler, 2006b). Similar perspectives can also be drawn from research on obedience to authority showing that individuals are more willing to obey authorities to whom they attribute strong legitimacy, such as the scientists (Kelman \& Hamilton, 1989; Milgram, 1974).

The power of legitimacy is not only limited to situations where authority's actions are inconsequential to group members. A number of studies in sociology have shown that authorities with strong legitimacy can promote acceptance of disadvantageous treatments (e.g. Cohen, 1986; Hegtvedt \& Johnson, 2000; Johnson \& Ford, 1996; Walker et al., 1986; Zelditch \& Walker, 1984). Legitimacy bolsters and nurtures legitimation of authority figures' actions and decisions, as well as possible adverse repercussions for the group. The more disadvantages are initiated by authorities who enjoy strong legitimacy, the more individuals feel that these disadvantages are tolerable and acceptable. Following Zelditch and Walker's theorization (1984), authority legitimacy fosters acceptance of unfair distribution by creating expectations that peers are supportive for such a distribution (i.e. endorsement) and that higher authorities have given their assent (i.e. authorization). Thus, legitimacy offers a powerful source of coercion as presupposing that others of the same rank and above consent to the authority's decisions, no matter how unfair they may be, and would adopt formal and informal sanctions in case of disobedience. Moreover, legitimacy provides a solid basis for external validation by dispelling uncertainties that could arise from a disadvantageous situation. Indeed, by acting in contradiction with certain principles of justice (e.g. by distributing more to someone without apparent motive), authorities are likely to arouse suspicions about potential irregularities in the normal course of events, which may stimulate action. Because it implies the endorsement of peers and authorization of higher authorities, legitimacy reduces uncertainty by giving credit and confidence in the decisions made, which in turn curtails resistance actions. In this sense, information about the legitimacy of authorities can be used as heuristics or situational cues to reduce uncertainty about what to think and how to act in an explicitly disadvantageous situation (for a close view, see Van den Bos et al., 2001).

Moreover, legitimacy has been found to mitigate negative emotional reactions to experiencing unfair situations, such as anger, but also frustration or resentment, 
which in turn reduce the propensity to cooperate with the authority (Johnson et al., 2000, 2016; Tyler \& Huo, 2002). Legitimacy acts as a brake on affectivebased motivational forces stimulated by injustice and attenuates their corresponding behavioural tendencies (i.e. resistance and opposition). According to Johnson et al. (2016), because they create uncertainty about one's own feelings and reinforce the fear of sanctions and ostracism, legitimacy processes act as control mechanisms by regulating the intensity of emotional responses to an unfair distribution of outcomes.

Although the effects of legitimacy have been widely documented in past research, only limited attention has been given as to whether legitimate figures of authority can equally alter individuals' participation in collective actions. Yet, while legitimacy may decrease feelings of anger and increase acceptance of detrimental decisions, it is reasonable to assume that intention to participate in collective actions could be reduced as well. In the face of unfavourable decisions resulting from a legitimate authority, it is plausible that people will be less prompt to actively take action. Accordingly, the purpose of this study was to expand the research on legitimacy of authority by examining whether legitimate authorities can reduce engagement in protest actions in response to collective disadvantages, notably through a reduction in anger.

\section{Legitimacy of Authority Figures and Violation of Moral Values}

In this research, we argued that legitimacy has the potential to restrict individuals' readiness to protest, but only when perceived disadvantages are relatively low. In contrast, we hypothesized that the legitimacy effects would be undermined when the sense of collective disadvantage reaches high levels. First, this is because a strong disadvantage would generate intense feelings of group-based anger that legitimacy could not mitigate. Second, when a decision is extremely disadvantageous, strong moral concerns would arise and freeze the capacity of legitimacy to mitigate anger and, in turn, engagement in collective actions.

Research has indeed shown that violation of moral beliefs can provoke very intense reactions, such as violent and deviant behaviours (Mullen \& Nadler, 2008). In addition, when rules or decisions are at odds with moral values, procedural justice and legitimacy have been shown to be discounted as relevant factors in judgment and cannot have a mitigating effect on compliance with authorities (Skitka, 2002; Skitka et al., 2009; Skitka \& Mullen, 2002; for a discussion, see Skitka \& Morgan, 2014). Legitimacy can protect against deleterious effects caused by an adverse decision to the extent moral standards are not significantly challenged. When moral convictions are at stake (as is the case, for example, in a situation of great injustice), individuals' principles of judgment are based on the sole moral value that they confer on the decision taken (i.e. Is it morally "right" or "wrong"?) and refrain from deferring to authorities, regardless of how legitimate they are. For example, Skitka et al. (2009) investigated people's reactions to court decisions involving intense moral values (e.g. legalization of physician-assisted suicide). They observed that moral beliefs are the main predictors of people's acceptance of decisions made by judges and not their legitimacy. Regardless of judicial authorities' perceived legitimacy, those who 
were morally opposed estimated the final decision to be less fair and expressed more rejection. To echo the argument developed above, an unfair situation might reveal to be at odds with individuals' moral stances and, as such, could dispel uncertainty on which the potential of legitimacy for action is drawn. Moral resonance relating to disadvantages signals that the situation is unambiguously irregular, thereby providing justification for actively engaging in resistance movements.

Studies have also shown that emotions arising from the violation of moral values would be too intense to be mitigated by authority legitimacy or fair procedures (e.g. Mullen \& Nadler, 2008; Mullen \& Skitka, 2006). Breaches with important moral values have been shown to trigger strong emotional reactions, such as moral outrage or anger (Molho et al., 2017; Tetlock et al., 2000; Van Zomeren \& Lodewijkx, 2005), which are automatic responses, often difficult to control (Haidt et al., 1993). This, in turn, guides justice judgments and strongly motivates to act in ways that maintain and preserve one's sense of morality (Skitka, 2002; Skitka et al., 2008). In other words, given that moral values are higher-order principles and meaningful stances, any transgression poses an acute threat, alerting individuals, through heightened emotions, that strong disadvantages are occurring and that appropriate responses are needed to remedy them (see Folger \& Cropanzano, 1998). In this case, the legitimacy of authority becomes of little use in reducing such emotional reactions and, consequently, protest reactions.

As a result, we contended that the level of perceived disadvantages could condition the effects of authority legitimacy on participation in collective actions. In particular, we expected that a legitimate authority would reduce willingness to engage in protest actions as a response to unfair decisions only when these decisions are weakly unfair, but not when they are strongly unfair. When individuals are subjected to very unfair decisions that would profoundly challenge their moral values, intense emotional reactions will overshadow the effect of legitimacy. Therefore, in the present research, we hypothesized an interaction between perceived disadvantage and legitimacy, so that legitimacy would only affect collective action intentions when disadvantage is relatively low. Under these conditions, because the authority's decisions are less likely to conflict with moral values, we predicted that violation of moral values should be lower, which would temper anger and, in turn, would reduce collective action tendencies. ${ }^{2}$ Conversely, a condition of strong disadvantage would fail to trigger such mitigation. In other words, perceived disadvantages would moderate the effects of authority legitimacy on intention to participate in collective actions, through the serial mediation of moral value violation and anger.

It is important to underscore that the present research's expectations are in line with a great deal of research that has recently been placed on moral issues in the study of collective actions (see Van Zomeren et al., 2018). This research indicates

\footnotetext{
${ }^{2}$ We are not suggesting that a condition of low injustice would not have moral implications, but rather that, at this level, moral convictions are sufficiently preserved for an authority to be able to assert its legitimacy as a source of coercion over group members. Consequently, the legitimacy, because it creates an obligation of deference to authority, replaces the application of moral standards, provided that individuals' moral system itself be not profoundly defied by the authority's actions or rules.
} 
notably that engagement in collective actions can be boosted when individuals moralize perceived disadvantages, that is, when perceived disadvantages derive from a violation of individuals' moral values or convictions (Kutlaca et al., 2019; Mazzoni et al., 2015; Van Zomeren \& Lodewijkx, 2005; Van Zomeren et al., 2011, 2012). For example, Mazzoni et al. (2015) conducted two survey studies with Italian activists and Italian citizens from general public in the context of the Italian Water Movement (i.e. which was a social movement protesting against the liberalization of water resources in Italy). They examined whether and how support for the movement may be linked to participants' moral values (i.e. notably, in this context, the fundamental right to water). They consistently found that activism was fuelled by the perception that one's moral values in terms of free access to water have been harmed. In addition, this relationship was mediated by identification to the movement. According to the authors' reasoning, support for collective actions is shaped by the extent to which perceived moral violation caused by disadvantage fits with a protest group identity. People are more likely to engage in a movement or politicized group whose identity and central social norms resonate with their own moral values and are directed at redressing moral violation (Van Zomeren et al., 2012). Our research will add to this research in studying the still under-examined relationship between perceived disadvantages and moral values on collective actions, while considering the moderating role of authority legitimacy, which in itself has been found to be highly associated with morality.

Beyond this, the present work sought to provide innovative and solid contributions to research. First, we intended to show that authority legitimacy plays a significant role in engagement in collective actions and that it should be distinguished from perceived injustice. Although both are closely related (see Hegtvedt et al., 2016), justice and legitimacy are conceptually distinct constructs. Justice, and notably distributive justice, refers to the perception that an allocation of resources from an authority does not benefit more other groups than one's group. Legitimacy corresponds to the perception that one person is entitled to exercise a position of power and authority over subordinates. In this sense, justice pertains to the actions enacted by an authority towards individuals, while legitimacy, more broadly, pertains to the person itself and appropriateness of his or her social position within a group. Accordingly, authority legitimacy differs conceptually from perceived injustice and cannot be considered as a mere dimension feeding justice perceptions. ${ }^{3}$ Besides, individuals can establish perceptions of justice quite independently of how they construct perceptions of legitimacy (Caldeira \& Gibson, 1992; Gibson, 1989). Research has shown that group authorities may be perceived high in legitimacy even if they allocate outcomes unfairly, notably because group members tend to attribute authority's unfair actions to external causes and to disclaim any responsibility for its wrongs (Hegtvedt et al., 2003; Hegdvedt \& Johnson, 2000). Therefore, it is

\footnotetext{
${ }^{3}$ In this regard, it is important to note that research has rather shown that justice (and notably procedural justice) might be best conceptualized as a component of legitimacy than the converse (see Colquitt et al., 2001, 2005; Hegtvedt \& Johnson, 2000; Tyler, 2006a).
} 
fundamental to differentiate legitimacy from perceived injustice in our understanding of engagement in collective actions.

Second, as a corollary, another important contribution of our research is to examine for the first time how authority legitimacy may mitigate the impact of perceived disadvantage on collective actions. Despite that research has repeatedly shown that both strongly interact in their effects on cooperation with authority figures (e.g. Hegtvedt et al., 2016; Walker, 2014; Walker et al., 1986; Zelditch \& Walker, 1984), the interaction between disadvantage and legitimacy on collective actions has never been addressed. Therefore, it is of great interest to analyse legitimacy independently from injustice and to examine how legitimacy and injustice perceptions both together affect collective actions and how they can allow to reconsider the wellestablished effect of perceived group disadvantage.

\section{The Present Research}

The current research sought to examine the role of authority legitimacy in the effects of collective disadvantages on intention to participate in protest actions. We conducted three studies using fictitious vignettes to manipulate authority legitimacy. In Study 1, we manipulated authority legitimacy with three levels (i.e. high, moderate, and low $),{ }^{4}$ while perceived disadvantage was held constant at a medium level. More specifically, we tested the following hypothesis:

$\mathrm{H} 1$ We expected that the more an authority is perceived as legitimate, the less people would intend to engage in protest actions in response to collective disadvantages.

In Studies 2 and 3, we manipulated both legitimacy and disadvantage (i.e. low vs. high + one condition with no-explicit disadvantage in Study 3) and examined the following hypothesis:

H2 We expected authority legitimacy to reduce collective action intentions only when disadvantage is low.

In all studies, we further examined the mechanism underlying the effects predicted in $\mathrm{H} 1$ and $\mathrm{H} 2$. In Studies 1 and 2, we looked at the mediating role of anger, while study 3 tested a moderated serial mediation model including violation of moral values and anger. The following hypotheses were tested:

H3 We expected anger to mediate the effect of authority legitimacy on collective action intentions.

\footnotetext{
4 We included a medium condition with the aim of examining the linearity of the relationship between legitimacy and collective action intentions, but also with the aim of offering a more nuanced and elaborated test of our hypotheses, which is often examined through only two conditions (i.e., high vs. low).
} 
$\mathrm{H} 4$ We expected anger to mediate the effect of authority legitimacy on collective action intentions only when disadvantage is low.

H5 We expected the effect of authority legitimacy on collective action intentions to be mediated by violation of moral values and then anger, but only when disadvantage is low.

\section{Study 1}

\section{Method}

\section{Participants and Procedure}

We determined the required sample size for this study by performing an a priori power analysis with G*Power v.3.1 (Faul et al., 2007), testing for a main effect with three independent groups. Based on a medium estimated effect size of $f=0.25$ and a desired statistical power of 0.80 (0.05 alpha level), it was established that we needed a minimum of 128 participants for the predicted main effect. Thus, 140 French undergraduate students were recruited and voluntarily took part in this study $\left(M_{\mathrm{Age}}=20.21, S D_{\mathrm{Age}}=2.16\right.$; women: $\left.N=81\right)$. They were randomly assigned to one of three experimental conditions (legitimacy: low vs. moderate vs. high). After consenting to the study, participants were instructed to read a fictitious vignette and imagine themselves as if they were working in a small company. They were told that a new manager was recently hired in this company by an independent recruitment firm. Upon his arrival, he announced that he intended to reorganize the way things work at the company in order to improve its productivity, which would require from employees to work extra hours for the same wage (i.e. which corresponds to the group disadvantage). The vignette then indicated that, after the meeting, some people showed their discontent and planned on taking action to oppose such a decision. Right after this, participants wrote down their thoughts about the vignette. They then completed measures of anger and collective action intention. Finally, they reported sociodemographics (i.e. sex and age) before being debriefed and thanked for their participation.

\section{Independent Variable}

Authority legitimacy was manipulated in the vignette by varying information about how the company's new boss was appointed. In the condition of high legitimacy, participants were informed that he was hired very impartially by the recruitment firm and that he met all the required qualifications to be the leader of the company. In the condition of moderate legitimacy, we also informed participants that the new boss' educational background was very well suited to the position. However, we added that he might have benefited from the help of someone he knew from the recruitment firm who got him the job by "pulling some strings". In the condition of low legitimacy, we outlined that the new boss was not appropriately qualified for the 
position and that he might have received support from someone in the recruitment firm.

Legitimacy was manipulated in a way to make it distinct from the disadvantage. Indeed, both concepts being relatively close, it may be easy to manipulate one while affecting the other. This is why we manipulated legitimacy by varying how someone is designated as the group authority (for a close procedure, see Hays \& Goldstein, 2015). In contrast, disadvantage here refers to the authority's actions towards group members (through the distribution of outcomes such as work time and salaries). By employing such a "distal" manipulation of legitimacy that disentangles the designation of the authority from its actions, we ensured that legitimacy does not intertwine with the effects of disadvantage and matches well with its definition.

A pilot study was carried out to verify whether this manipulation can elicit expected levels of legitimacy. Thirty-eight undergraduate students had to read one of three scenarios and then to report, on 7-point rating scales ranging from 1 (=not at all) to 7 (=yes absolutely), whether they believe that it is "legitimate" and "fair" that the new boss holds his or her position $(r=0.79, p<0.001)$. Results gave evidence for a linear relationship between the experimental conditions and perceived legitimacy, $\beta=0.82, S E=0.21, t=9.004, p<0.001,95 \% \mathrm{CI}=[1.483,2.346]$. The new boss was rated to be more legitimate in the condition of high legitimacy $(M=5.96, S D=1.12)$ than in the condition of moderate legitimacy $(M=4.80, S D=1.16)$, and even more than in the condition of low legitimacy $(M=2.13, S D=1.09)$.

\section{Measures}

First, we measured anger with two items (i.e. participants had to report whether, in the situation detailed in the vignette, they would have felt "angry" and "furious" after the new boss has announced his decision; $r=0.80, p<0.001)$. Second, intention to participate in collective actions was assessed with two items asking participants "whether they approve the protesters' actions" and "whether they would like to participate in the protesters' actions". For ecological validity reasons, we gave examples of actions, such as "signing petitions" or "going on strike". Both items were averaged $(r=0.68, p<0.001)$. Both measures were accompanied with response scales ranging from 1 (=not at all) to 7 (=yes absolutely).

\footnotetext{
5 Drawing upon earlier works showing that collective actions can take several forms, ranging from moderate (or normative collective actions, i.e. actions that are in line with the acceptable norms in the dominant social system) to radical forms of (or non-normative collective actions; i.e., actions that break with such norms) collective actions (Becker \& Tausch, 2015; Tausch et al., 2011), we also asked participants, for exploratory purposes, for their intention to participate in non-normative forms of collective actions (i.e., same questions were asked, but different examples were given, like "illegal occupation of workplaces", "destruction of work-related equipment and materials", or "use of violence"). But for the sake of clarity and conciseness, we did not report the corresponding findings in the manuscript, but as supplementary information.
} 


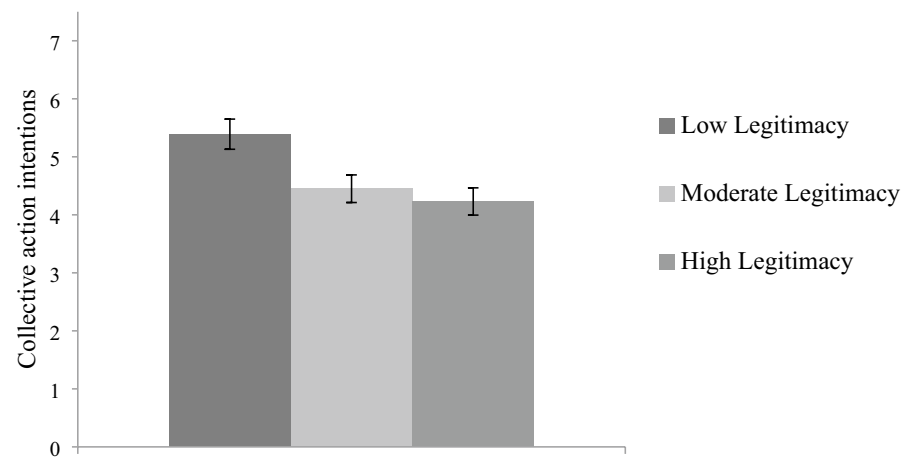

Fig. 1 Collective action intentions as a function of authority legitimacy Note Error bars represent standard errors

\section{Results}

To test $\mathrm{H} 1$ and $\mathrm{H} 3$, we created two orthogonal contrasts, namely $\mathrm{C} 1$, as the planned contrast (conditions were coded as follows: low legitimacy $=-1$, moderate legitimacy $=0$, high legitimacy $=+1),{ }^{6}$ and $\mathrm{C} 2$, as the residual. (Conditions were coded as follows: low legitimacy $=+1$, moderate legitimacy $=-2$, high legitimacy $=+1$.) To conclude for the linear effect of legitimacy, C1 must be significant, while C2 should not (see Abelson \& Prentice, 1997).

\section{Manipulation Check}

To check for our manipulation, we asked participants to complete the same measure as the one used in the pilot study $(r=0.80, p<0.001)$. Results showed that $\mathrm{C} 1$ was significant, $\beta=0.77, S E=0.13, t=14.46, p<0.001,95 \% \mathrm{CI}=[1.620,2.133]$, $\eta_{p}^{2}=0.60$, while $\mathrm{C} 2$ was not, $\beta=0.10, p=0.066$. Thus, as we expected, the new boss was judged to be more legitimate in the condition of high legitimacy $(M=6.01$, $S D=1.09)$ than in the condition of moderate legitimacy $(M=4.55, S D=1.37)$, and more legitimate in the condition of moderate legitimacy than in the condition of low legitimacy $(M=2.26, S D=1.19)$.

\section{Anger}

Analyses showed that $\mathrm{C} 1$ was significant, $\beta=-0.40, S E=0.17, t=-5.03, p<0.001$, $95 \% \mathrm{CI}=[-1.190,-0.518], \eta_{p}^{2}=0.16$, while $\mathrm{C} 2$ was not, $\beta=-0.10, p=0.231$. This indicates that participants felt less anger in the high legitimacy condition $(M=2.85$,

\footnotetext{
${ }^{6}$ Given that we expected that the more legitimacy is high, the less people would be willing to participate in collective actions, we tested here a linear relationship between the three conditions of legitimacy, so that differences are anticipated between all the conditions, with the medium condition in between.
} 


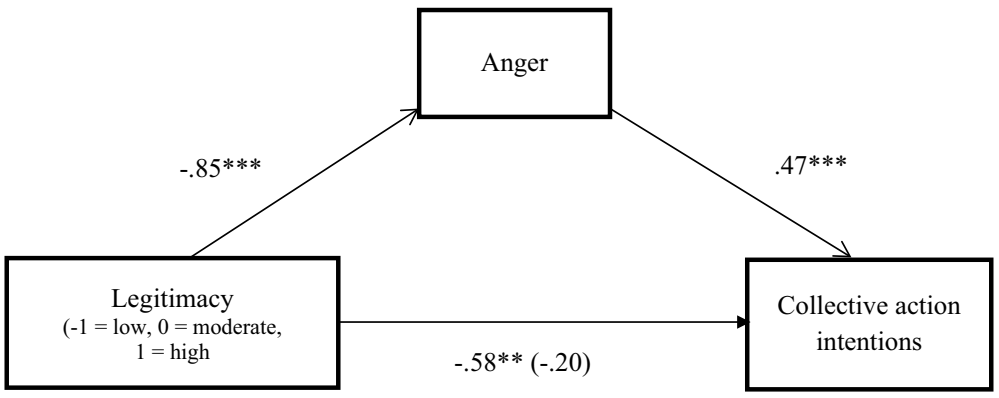

Fig. 2 Mediation (Study 1) Note For visual clarity, we omitted paths including C2; ${ }^{*} p<.05$, ** $p<.01$, $* * * p<.001$

$S D=1.48)$ than in the moderate legitimacy condition $(M=4.05, S D=1.73)$ and than in the low legitimacy condition $(M=4.56, S D=1.58)$.

\section{Collective Action Intentions}

We found a significant effect of $\mathrm{C} 1, \beta=-0.27, S E=0.18, t=-3.31, p=0.001,95 \%$ $\mathrm{CI}=[-0.926,-0.233], \eta_{p}^{2}=0.07$, but not of $\mathrm{C} 2, \beta=0.10, p=0.222$. Intention to take part in collective actions was the lowest when legitimacy was high $(M=4.23$, $S D=1.83)$ and the highest when legitimacy was low $(M=5.39, S D=1.58)$. The moderate condition fell in between $(M=4.45, S D=1.60$; see Fig. 1).

\section{Mediation Analyses}

To test whether anger mediated the effect of legitimacy on intention to engage in collective actions, we run a mediation analysis by using the PROCESS macro (Model 4; Hayes, 2013) with 5000 bootstrap re-samples. We entered C1 as the predictor, anger as the mediator, intention to engage in collective actions as the predicted variables, and $\mathrm{C} 2$ as a covariate. In line with $\mathrm{H} 3$, we found a significant indirect effect, $B=-0.38, S E=0.10,95 \% \mathrm{CI}=[-0.582,-0.210]$ (see Fig. 2).

\section{Discussion}

Consistent with $\mathrm{H} 1$ and $\mathrm{H} 3$, the present results showed that, in the face of disadvantageous decisions, increased authority legitimacy reduced willingness to participate in collective actions. Moreover, anger mediated this effect.

\section{Study 2}

While Study 1 held the level of disadvantage constant, the purpose of Study 2 was to manipulate it and compare the effect of legitimacy on intention to participate in collective actions when disadvantage is low or high. In line with $\mathrm{H} 2$, we predicted that 
an authority with high legitimacy can attenuate collective action motivation only when disadvantage is low. In contrast, when disadvantage is high, legitimacy could no longer have an impact on individuals' motivation to take action. In addition, we were also interested in examining whether the intensity of disadvantage could affect the mediation by anger (see H4). To the extent that high disadvantage instigates high levels of anger, regardless of legitimacy, anger could not be reduced and therefore should not play a mediating role between legitimacy and collective action intention. Procedure and experimental materials of Study 2 are similar to Study 1, the only difference being the manipulation of disadvantage.

\section{Method}

\section{Participants and Procedure}

Reporting the same effect size as in Study $1(f=0.25)$ and a desired statistical power of 0.80 , we again performed an a priori power analysis with $\mathrm{G}^{*}$ Power, testing, this time, an interaction effect, with six groups in total. This indicated that we needed a minimum of 155 participants. We recruited a total of 228 French undergraduate students who voluntarily participated in this study $\left(M_{\text {Age }}=19.42, S D_{\text {Age }}=1.72\right.$; women: $\left.N=186\right)$. They were randomly allocated to one of six experimental conditions of a 3 (legitimacy: high vs. moderate vs. low) $\times 2$ (disadvantage: low vs. high) between-subject factorial design. Similar to Study 1, participants were instructed to read the same vignette (including the additional manipulation of disadvantage) before completing the measures of anger and collective action intention. Finally, they were asked for their sex and age and were debriefed and thanked for their participation.

\section{Independent Variables}

We used the same manipulation of legitimacy as in Study 1. To manipulate the level of disadvantage, we provided participants with some information about the authority's decisions on changing the way things work in the workplace. In the condition of low disadvantage, participants read that the changes included longer working time but, as a compensation, a significant increase in the employees' salary. In contrast, in the condition of high disadvantage, participants were told that in addition to longer working time, there will be significant cuts in their salary. It is important to note that the low disadvantage condition, which might appear as being quite advantageous because a financial compensation is offered, still remains disadvantageous because people are requested to work more than they used to do before. One may easily assume that the increase in salary could not fully compensate for the inconveniences caused by such an increase in working time. Besides, not all individuals want to earn more money in their work, some just do not want to work more. 


\section{Measures}

We measured anger and intention to participate in collective actions with the same items as in Study 1. Reliability of these measures proved to be satisfactory (anger: $r=0.83, p<0.001$; intention: $r=0.72, p<0.001)$.

\section{Results}

Hypotheses were tested by computing the same contrasts as in Study 1. We performed multiple regression analyses with $\mathrm{C} 1, \mathrm{C} 2$, disadvantage (coded as follows:- $1=$ low, $1=$ high), and the two interaction products between disadvantage and each contrast. We concluded on significance of the interaction between the two independent variables with the conditions of legitimacy varying with each other when the product including $\mathrm{C} 1$ was significant, while the product including $\mathrm{C} 2$ was not.

\section{Manipulation Checks}

Using the same items as in Study 1 to check for the manipulation of legitimacy ( $r=0.83, p<0.001$ ), analyses showed a significant effect of $\mathrm{C} 1, \beta=0.79, S E=0.10$, $t=19.47, p<0.001,95 \% \mathrm{CI}=[1.735,2.126], \eta_{p}^{2}=0.62$, and a significant (though weaker) effect of $\mathrm{C} 2, \beta=0.09, S E=0.06, t=2.18, p=0.030,95 \% \mathrm{CI}=[0.012$, $0.236], \eta_{p}^{2}=0.02$. The new boss was evaluated as more legitimate in the condition of high legitimacy $(M=6.04, S D=1.07)$ than in the condition of moderate legitimacy $(M=4.48, S D=1.37)$, and more legitimate in the condition of moderate legitimacy than in the condition of low legitimacy $(M=2.18, S D=2.00)$. The disadvantage variable was checked through one single item, which asked participants to report, on a 7-point rating scale, whether "they think that the new organization of work was fair". Supporting the efficacy of our manipulation, participants evaluated the new organization of work to be less fair in the condition of high disadvantage $(M=3.18, S D=1.88)$ than in the condition of low disadvantage $(M=4.84$, $S D=1.83), t(229)=6.82, p<0.001,95 \% \mathrm{CI}=[1.182,2.143]$.

\section{Anger}

Analyses revealed a main effect of $\mathrm{C} 1, \beta=-0.20, S E=0.12, t=-3.63, p<0.001$, $95 \% \mathrm{CI}=[-0.696,-0.207], \eta_{p}^{2}=0.06$, but not of $\mathrm{C} 2, \beta=0.08, p=0.135$. We also found a main effect of disadvantage, $\beta=0.49, S E=0.10, t=8.84, p<0.001,95 \%$ $\mathrm{CI}=[0.694,1.092], \eta_{p}^{2}=0.26$. More importantly, we found the expected interaction between $\mathrm{C} 1$ and disadvantage, $\beta=-0.15, S E=0.12, t=-2.60, p=0.010,95 \%$ $\mathrm{CI}=[-0.567,-0.078], \eta_{p}^{2}=0.03$, while the interaction with $\mathrm{C} 2$ was not significant, $\beta=0.02, p=0.773$. Decomposition of this interaction showed that $\mathrm{C} 1$ was non-significant in the condition of high disadvantage, $\beta=-0.06, p=0.456$, but was significant in the condition of low disadvantage $\beta=-0.35, S E=0.18, t=-4.34, p<0.001$, 


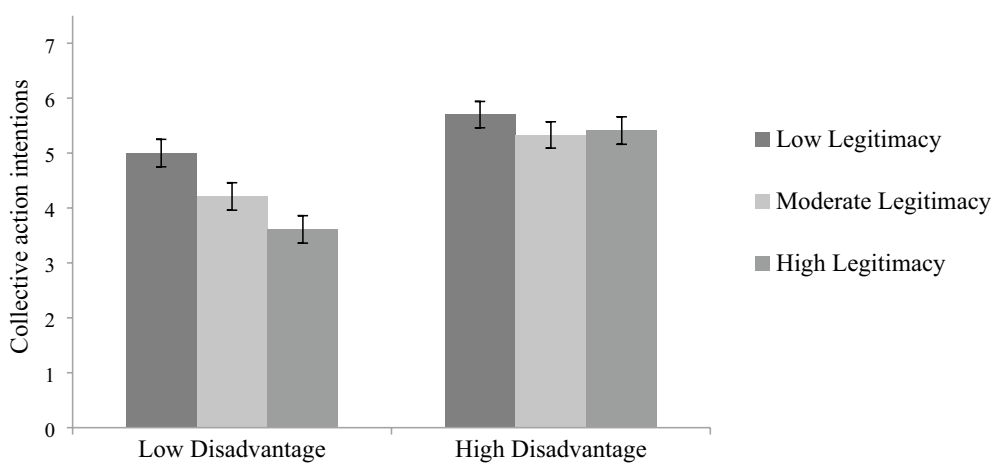

Fig. 3 Collective action intentions as a function of legitimacy and disadvantage Note Error bars represent standard errors

95\% $\mathrm{CI}=[-1.125,-0.422], \eta_{p}^{2}=0.08$, thus indicating that anger was lower when legitimacy was high $(M=2.20, S D=1.15)$ than moderate $(M=2.59, S D=1.52)$ and than low $(M=3.75, S D=1.35)$. C2 was not significant in both conditions of disadvantage $(p s>0.20)$.

\section{Collective Action Intentions}

We found a significant main effect of $\mathrm{C} 1, \beta=-0.21, S E=0.12, t=-3.39, p=0.001$, $95 \% \mathrm{CI}=[-0.665,-0.177], \eta_{p}^{2}=0.05$, while $\mathrm{C} 2$ was non-significant, $\beta=0.05$, $p=0.459$. Moreover, we found a main effect of disadvantage, $\beta=0.36, S E=0.10$, $t=5.96, p<0.001,95 \% \mathrm{CI}=[0.402,0.800], \eta_{p}^{2}=0.14$. Consistent with $\mathrm{H} 2$, results also showed that the interaction between $\mathrm{C} 1$ and disadvantage was significant, $\beta=-0.13, S E=0.12, t=-2.22, p=0.028,95 \% \mathrm{CI}=[-0.519,-0.031], \eta_{p}^{2}=0.02$, while the interaction with $\mathrm{C} 2$ was not, $\beta=0.02, p=0.741$. Decompositions indicated that $\mathrm{C} 1$ was not significant in the condition of high disadvantage, $\beta=-0.07$, $p=0.398$, but was significant when disadvantage was low, $\beta=-0.34, S E=0.18$, $t=-3.90, p<0.001,95 \% \mathrm{CI}=[-1.047,-0.345], \eta_{p}^{2}=0.06$. In this condition, collective action intentions decreased as authority legitimacy increased, with the high legitimacy condition $(M=3.61, S D=1.61)$ being lower than the low legitimacy condition $(M=5.00, S D=1.49)$, and the moderate legitimacy condition in between $(M=4.22, S D=1.59$; see Fig. 3). Note that $\mathrm{C} 2$ was not significant in both conditions of disadvantage $(p s>0.40)$.

\section{Moderated Mediation Analyses}

Finally, we examined whether group disadvantage moderated the mediation of anger in the relationship between legitimacy and collective action intention. To do so, we performed moderated mediation analyses by using the PROCESS Model 8 with 5000 bootstrap re-samples. C1 was entered into the analyses as the predictor, anger as the mediator, collective action intentions as the predicted variables, disadvantage as the moderator, and $\mathrm{C} 2$ and the $\mathrm{C} 2 *$ legitimacy interaction as covariates. 


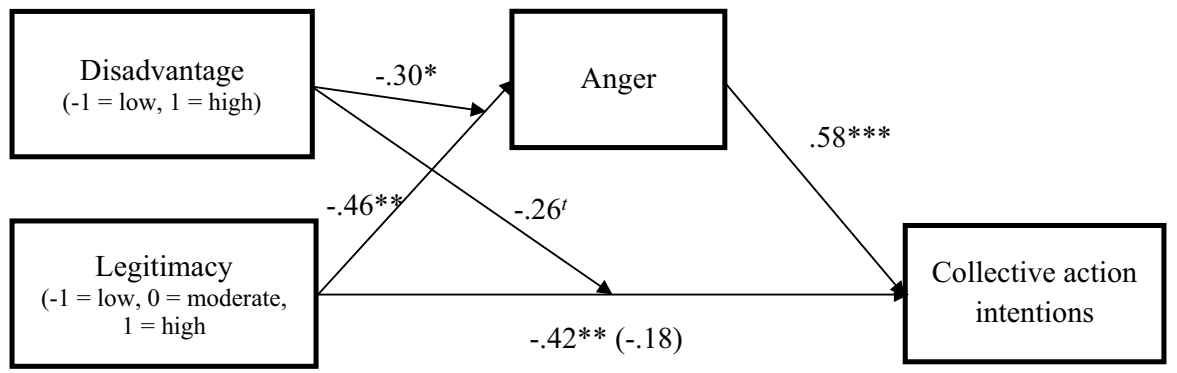

Fig. 4 Moderated mediation (Study 2) Note For visual clarity, we omitted paths including C2 and the interaction between $\mathrm{C} 2$ and disadvantage; ${ }^{t} p<.10, * p<.05, * * p<.01, * * * p<.001$

This analysis showed that the index of moderated mediation was significant, $B=-0.34, S E=0.13,95 \% \mathrm{CI}=[-0.603,-0.085]$. More specifically, we observed that anger mediated the relationship between legitimacy and collective action intentions in the condition of low disadvantage, $B=-0.40, S E=0.09,95 \% \mathrm{CI}=[-0.591$, -0.230 ], but not in the condition of high disadvantage, $B=-0.07, S E=0.10,95 \%$ $\mathrm{CI}=[-0.276,0.125]$. This analysis is plotted in Fig. 4 .

\section{Discussion}

Consistent with $\mathrm{H} 2$ and $\mathrm{H} 4$, the present study evidenced that legitimacy reduced collective action intentions in response to low disadvantages. However, when participants faced high disadvantages, our findings revealed that legitimacy was not influential on neither anger nor willingness to participate in collective actions. Relatedly, moderated mediation analyses provided evidence that the mediation of anger only occurred when disadvantage was low.

\section{Study 3}

Study 3 was an attempt to replicate and extent the Study 2's findings by further examining the mechanisms underlying the interplay of legitimacy and disadvantage on collective action intentions. While previous studies addressed anger as a mediator, the current study focused on both anger and violation of moral values. In line with $\mathrm{H} 5$, we predicted that legitimacy and disadvantage may interactively relate to collective action intentions not only through anger but also through violation of moral values. More specifically, we predicted that authority legitimacy should mitigate motivation to engage in collective actions by first reducing perception of violation of moral values and then anger, but only when disadvantage is low. However, when disadvantage is high, legitimacy should no longer predict collective action intentions, precisely because violation of moral values and anger cannot be alleviated. Thus, a model of moderated serial mediation was analysed to test such predictions. 
Methodologically speaking, procedure and experimental materials were similar to Study 1 and 2, notwithstanding three main changes. First, whereas the previous study compared the effect of low disadvantage to a condition of high disadvantage, in this new study we additionally included a condition with supposedly no disadvantages. In doing so, we aimed to examine whether the effect of legitimacy is exclusive of low levels of disadvantages or might arise even in the absence of explicit disadvantages. Drawing on earlier works showing that legitimacy may increase acceptance of authority's decisions, even when those are not particularly disadvantageous (e.g. Tyler \& Huo, 2002; Tyler, 2006a), we expected legitimacy to work alike in both the no-explicit and low disadvantage conditions. Second, whereas Study 2 manipulated three levels of legitimacy (i.e. low, moderate, and high), in this study we only included two experimental conditions (i.e. low vs. high). Third, since our vignettes played out in a work setting, we sought to only recruit working participants, for whom this environment should be particularly relevant. As such, this could address a possible limitation in our previous studies that undergraduate students, who may be quite unfamiliar with work environments, could have inadequately imagined themselves in the vignette scenario and reacted without being really aware of the consequences and issues occurring at work, especially when it comes to decide on protesting (e.g. fear of dismissal).

\section{Method}

\section{Participants and Procedure}

Given that an identical experimental design as in the previous study was tested here again, sample size determination remained also the same. We approached a total sample of 302 participants by using the recruitment website Prolific with a monetary compensation of $1 £\left(M_{\text {Age }}=37.24, S D_{\text {Age }}=10.48\right.$; women: $\left.n=177\right)$. Most of them were British $(n=287)$, and all the participants' country of residence was the UK. All were working in a company when they completed the study: $32.8 \%$ reported being administrative personnel, $17.9 \%$ business managers, $15.6 \%$ technicians, and $10.6 \%$ higher executives or major professionals. On average, they had been working for 6.70 years $(S D=6.01)$, and $80.3 \%$ had a full-time job. They were randomly allocated to one of the six experimental conditions of a 2 (legitimacy: low vs. high) $\times 3$ (disadvantages: low vs. high vs. no-explicit disadvantage) between-subject factorial design. The procedure was similar to the previous studies.

\section{Independent Variables}

Manipulations of disadvantage and legitimacy only included some few changes compared with the previous studies. In order to simplify the experimental design, we decided to compare the conditions of high and low legitimacy only and remove the medium condition. Regarding the disadvantage variable, we additionally included a control condition with no-explicit disadvantage. Participants were told that the new boss intends to reorganize the company to improve productivity, without this 
being supposed to have implications on the employees' working time and salary. It is worthwhile noting that this control condition was labelled as a "no explicit disadvantage" condition. Although no disadvantage was overtly described in the scenario, it is clear that individuals can still infer the presence of disadvantages. First, the vignette specified that the new boss wants to initiate a change in the work organization. One can assume that this may in itself constitute a collective disadvantage (even though this is not personally involving), or that this may fuel the fear that disadvantages might occur sooner or later (such as dismissals). Second, even if the changes in work organization are supposed to have no implications for employees' work time and salary, the mere fact that some were depicted to protest against it may potentially lead to believe that the changes might result in personally relevant disadvantages (other than salary and working time).

\section{Measures $^{7}$}

Unless otherwise specified, all responses to the following measures were given on 7 -point rating scales ranging from 1 (=not at all) to 7 (=yes absolutely).

\section{Anger}

We assessed anger with five items. Participants had to report whether they felt "angry", "furious", "irritated", "outraged", and "indignant" in reaction to the new boss' decision $(\alpha=0.96 ; M=3.71, S D=1.75){ }^{8}$

\section{Violation of Moral Values}

Perceived violation of moral values was measured with three items: "The decision made by the new company's boss has clearly violated my moral values", "I think that the decision made by the new company's boss is immoral", "The decision made by the new company's boss conflicts with the moral beliefs that are important to me" $(\alpha=0.92 ; M=3.60, S D=1.79)$.

\footnotetext{
7 For exploratory purposes, the present study also measured group efficacy, identification with the protesters, and moral convictions. Since these variables are central to understanding engagement in collective actions (VanZomeren et al., 2008), they were additionally included in the study. However, as they deviated from our initial theoretical framework, we did not raise particular hypotheses about them. Therefore, for greater clarity, details about the measures and results were not reported in the manuscript but as supplementary materials.

8 Initially, we differentiated between a measure of anger (as assessed in Studies 1 and 2) and moral outrage (assessed with the three additional items; see Thomas \& McGarty, 2009). However, after running factorial analyses, it turned out that only one factor with eigenvalues greater than 1 was extracted, accounting for $85.58 \%$ of the total variance, and with very high factor loadings going from .89 to .95 . Consequently, we concluded that both constructs were not clearly distinguished in participants' mind and decided to aggregate all five items within one single measure.
} 


\section{Collective Action Intentions}

Differently from previous studies, we assessed intention to participate in a collective action with five items asking participants whether they would be willing to help the protesters "organize and take part in a strike", "create and distribute a petition", "organize and participate in a demonstration", "distribute flyers", and "organize information sharing and discussion sessions" (see Teixeira et al., 2020, for a similar measure; $\alpha=0.94 ; M=3.08, S D=1.70$ ).

\section{Results}

We tested our hypotheses by computing two contrasts: $\mathrm{C} 1$, as the planned contrast (with conditions of disadvantage coded as follows: no-explicit disadvantage $=-1$, low $=-1$, high $=+2$ ), and $\mathrm{C} 2$, as the residual (with conditions coded as follows: low $=-1$, no-explicit disadvantage $=+1$, high $=0$ ). We then performed multiple regression analyses with $\mathrm{C} 1, \mathrm{C} 2$, legitimacy (coded as follows: $-1=$ low,$+1=$ high), and the two interaction products between legitimacy and each contrast.

\section{Manipulation Checks}

As a check for the legitimacy manipulation, we used the same items as in Studies 1 and $2(r=0.95, p<0.001)$. As expected, participants rated the new boss to be more legitimate in the condition of high legitimacy $(M=5.55, S D=1.68)$ than in the condition of low legitimacy $(M=2.10, S D=1.15), t(300)=20.71, p<0.001$, $95 \% \mathrm{CI}=[3.116,3.770]$. Regarding the manipulation of disadvantage, which was measured with the same single item as in Study 2, we found a significant effect of $\mathrm{C} 1, \beta=0.52, S E=0.06, t=10.63, p<0.001,95 \% \mathrm{CI}=[0.524,0.762]$, and a nonsignificant effect of $\mathrm{C} 2, \beta=-0.09, p=0.074$. The new boss' decision was evaluated as less fair in the condition of high disadvantage $(M=2.36, S D=1.25)$ than in the conditions of low $(M=4.10, S D=1.53)$ and no-explicit disadvantage $(M=4.47$, $S D=1.66)$.

\section{Anger}

On anger, we found a main effect of legitimacy, $\beta=-0.28, S E=0.08, t=-6.27$, $p<0.001,95 \% \mathrm{CI}=[-0.643,-0.336], \eta_{p}^{2}=0.12$. Moreover, we found a significant interaction between legitimacy and $\mathrm{C} 1, \beta=-0.17, S E=0.06, t=-3.86, p<0.001$, $95 \% \mathrm{CI}=[-0.104,-0.321], \eta_{p}^{2}=0.05$, while the interaction with $\mathrm{C} 2$ was non-significant, $\beta=0.03, p=0.536$. Decomposition analyses for this significant interaction showed that legitimacy had a significant effect on anger in the conditions of low (LD) and no-explicit disadvantage (NED), $\beta=-0.40, S E=0.10, t=-7.24$, $p<0.001,95 \% \mathrm{CI}=[-0.888,-0.508], \eta_{p}^{2}=0.15$, such that participants reported being less angry when legitimacy was high $\left(M_{L D}=2.65, S E_{L D}=0.19 ; M_{N E D}=2.05\right.$, 


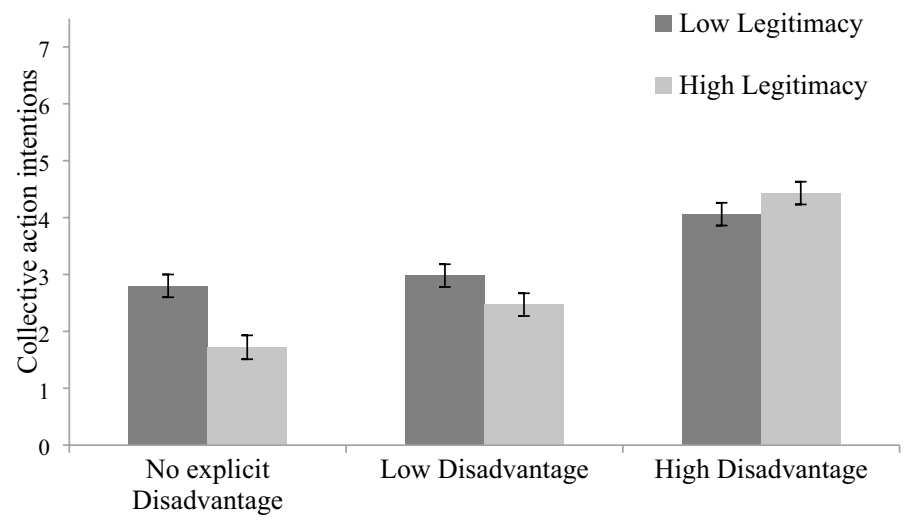

Fig. 5 Collective action intentions as a function of legitimacy and disadvantage Note Error bars represent standard errors

$S E_{N E D}=0.19$, respectively) rather than low $\left(M_{L D}=3.94, S E_{L D}=0.19 ; M_{N E D}=3.57\right.$, $S E_{N E D}=0.19$, respectively). However, the effect of legitimacy was not significant in the condition of high disadvantage, $\beta=0.04, p=0.640$.

\section{Violation of Moral Values}

Legitimacy was found to produce a main effect, $\beta=-0.24, S E=0.08, t=-5.06$, $p<0.001,95 \% \mathrm{CI}=[-0.592,-0.260], \eta_{p}^{2}=0.08$. The interaction between $\mathrm{C} 1$ and legitimacy was also found to be significant, $\beta=-0.20, S E=0.06, t=-4.15$, $p<0.001,95 \% \mathrm{CI}=[-0.364,-0.130], \eta_{p}^{2}=0.06$, while the interaction with $\mathrm{C} 2$ was not, $\beta=0.08, p=0.078$. Decomposition of the significant interaction showed that legitimacy predicted violation in both the no-explicit and low disadvantage conditions, $\beta=-0.37, S E=0.11, t=-6.31, p<0.001,95 \% \mathrm{CI}=[-0.872,-0.458], \eta_{p}^{2}=$ 0.12 , so that participants perceived that their moral values are less violated when legitimacy was high $\left(M_{L D}=2.86, S E_{L D}=0.20 ; M_{N E D}=1.79, S E_{N E D}=0.21\right.$, respectively), rather than low $\left(M_{L D}=3.84, S E_{L D}=0.21 ; M_{N E D}=3.50, S E_{N E D}=0.21\right.$, respectively). However, the effect of legitimacy was not significant in the condition of high disadvantage, $\beta=0.04, p=0.647$.

\section{Collective Action Intentions}

Legitimacy had a significant main effect, $\beta=-0.12, S E=0.08, t=-2.45, p=0.015$, $95 \% \mathrm{CI}=[-0.366,-0.040], \eta_{p}^{2}=0.02$. As predicted, we also found a significant $\mathrm{C} 1 *$ legitimacy interaction, $\beta=-0.16, S E=0.06, t=-3.32, p=0.001,95 \%$ $\mathrm{CI}=[-0.310,-0.079], \eta_{p}^{2}=0.04$, while the $\mathrm{C} 2 *$ legitimacy interaction was not significant, $\beta=0.07, p=0.164$ (see Fig. 5). Decomposing this significant interaction showed that legitimacy predicted collective action intentions in the low and no-explicit disadvantage conditions, $\beta=-0.23, S E=0.10, t=-3.82, p<0.001,95 \%$ $\mathrm{CI}=[-0.593,-0.190], \eta_{p}^{2}=0.05$. High legitimacy produced lower intentions to 


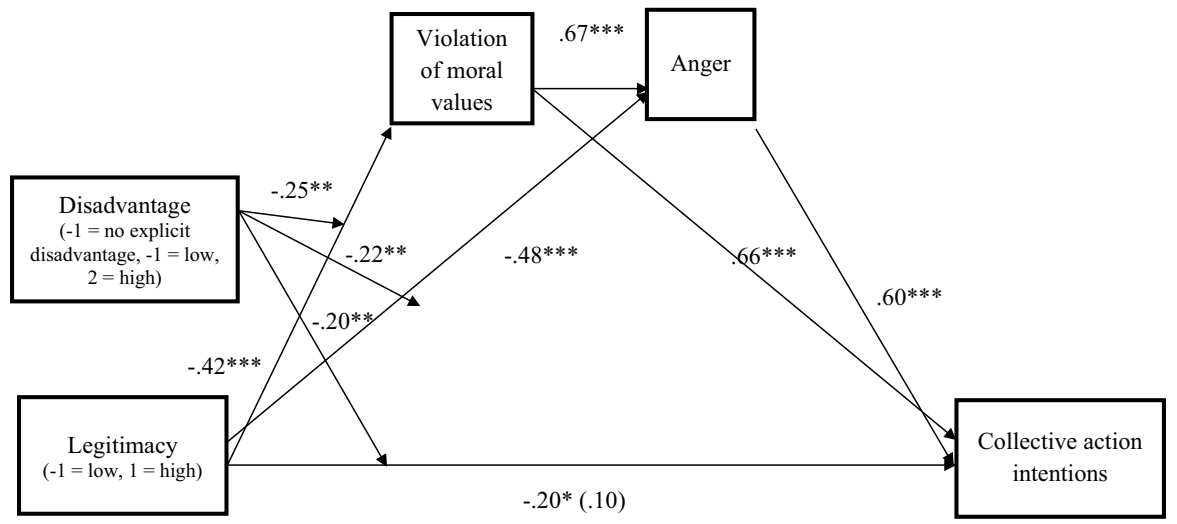

Fig. 6 Moderated serial mediation (Study 3) Note For visual clarity, we omitted paths including C2 and the interaction between $\mathrm{C} 2$ and legitimacy; ${ }^{*} p<.05, * * p<.01, * * * p<.001$

engage in collective actions $\left(M_{L D}=2.47, S E_{L D}=0.20 ; M_{N E D}=1.72, S E_{N E D}=0.21\right.$, respectively) than did low legitimacy $\left(M_{L D}=2.98, S E_{L D}=0.20 ; M_{N E D}=2.80\right.$, $S E_{N E D}=0.20$, respectively). However, the effect of legitimacy was not significant in the condition of high disadvantage, $\beta=0.11, p=0.200$.

\section{Moderated Serial Mediation Analyses}

As a test for the predicted moderated serial mediation, we used the model 85 of the PROCESS macro. Legitimacy was entered as the independent variable $(\mathrm{X}), \mathrm{C} 1$ as a moderator (W), and collective action intentions as the main outcome (Y). The mediators were successively perceived violation of moral values $\left(\mathrm{M}_{1}\right)$, and anger $\left(\mathrm{M}_{2}\right) . \mathrm{C} 2$ and the interaction product between $\mathrm{C} 2$ and legitimacy were included as covariates. The overall index of moderated mediation revealed to be significant, $B=-0.07, S E=0.03,95 \% \mathrm{CI}=[-0.151,-0.015]$. Moreover, we found that the path going from legitimacy to collective action intentions through first violation of moral values and then anger is significant only in the combined conditions of no-explicit and low disadvantage, $B=-0.06, S E=0.03,95 \% \mathrm{CI}=[-0.123,-0.016]$, and not in the condition of high disadvantage, $B=0.007, S E=0.02,95 \% \mathrm{CI}=[-0.022,0.043]$ (see Fig. 6).

\section{Discussion}

Based on a sample of working participants, this study corroborated findings of Study 2. Consistent with H2, we found that high (vs. low) legitimacy reduced intention to take part in a collective action when group disadvantage was relatively low, but not when people faced high disadvantage. Also, the fact that both the conditions of no-explicit and low disadvantage showed similar tendencies suggests that the effect of legitimacy can occur as long as disadvantages are not high. Moreover, the present findings revealed that moral issues account for the interaction between 
legitimacy and disadvantage on collective action intentions. Consistent with H5, we found that low levels of disadvantage allow for legitimacy to reduce individuals' desire to engage in a collective action, because it first reduced the overall perception that moral values are transgressed, which subsequently attenuated anger. In contrast, high levels of disadvantage disrupted the effects of legitimacy, mostly because perception of moral violation and feeling of anger could not be reduced, which propelled a strong motivation for collective actions, regardless of the level of legitimacy.

\section{General Discussion}

Taken as a whole, the results observed in the present studies provided convergent support for our main hypothesis (H1) according to which intention to engage in collective actions to redress group disadvantage is likely to be reduced when ingroup authority is perceived to be legitimate. Consistent with $\mathrm{H} 2$, we also found that the level of disadvantage plays a crucial role, given that the effect of authority legitimacy appeared under low or moderate levels of disadvantage (or even when disadvantage was not made explicit) but not when the authority's decisions were highly disadvantageous to group members. In an effort to understand the psychosocial dynamics underlying these results, mediation and moderated mediation analyses showed that legitimate authorities decreased the willingness to engage in protest actions because legitimacy contributes to tempering anger resulting from perceived injustice, but only in the condition of low disadvantage (and not when disadvantage was high). These findings were thus consistent with $\mathrm{H} 3$ and H4. Finally, in line with H5, Study 3 highlighted the key role played by morality: only in the case of a relatively low perceived disadvantage (and not when disadvantage was high), authority legitimacy sequentially reduced the perception of moral value violation and, in turn, anger, which ultimately accounted for reduced intention to participate in collective actions.

\section{Theoretical Implications}

These results have important theoretical implications for research on legitimacy of authority figures or group leaders. We provided evidence that the attenuating effect of legitimacy not only applies to emotions and compliance with authority (e.g. Cohen, 1986; Hegtvedt \& Johnson, 2000; Johnson et al., 2016), but also to protest behaviours. This finding suggests that legitimacy is a powerful factor that guarantees group members' compliance and cooperation with authority, as well as less opposition. By fuelling the legitimization of disadvantages, authority legitimacy renders the justification of any form of protest invalid, thereby discouraging involvement in social movements. Therefore, legitimacy would be underpinned by a belief whereby people ought to comply with the authorities and to suppress any resistance forces. From this perspective, legitimacy gives a crucial political weapon to maintain the authority's power and to limit the sources of rebellion that may arise in the face of 
a decision with deleterious consequences for group members. It equips governance structures with an aura of protection securing the maintenance of their power and the exercise of their authority over group members while imposing changes that are detrimental to them. Besides, it is in the belief in the legitimacy of authorities that group members find the reasons for legitimizing unfair treatments and their temperament to oppose the hierarchy. However, such a "legitimate domination" is inherently unequal and contributes tremendously to perpetuating the disadvantages of those who are powerless by making them refrain from denouncing inequalities and fighting for justice and better living standards (see Walker, 2014).

However, the power of legitimate authorities in reducing protest tendencies is not unlimited. As we have demonstrated in our studies, the level of authority legitimacy can alter collective action intentions only in conditions depicting relatively low collective disadvantages. In Study 1, the disadvantages can be qualified as moderate (i.e. there was an increase in work time, but salary was left untouched), while they were either low or implicitly mentioned in Studies 2 and 3. As expected, the same pattern of results consistently came out in all these conditions. Taken as a whole, they have in common that the disadvantages can easily be accepted and justified by external reasons (i.e. beyond the authority's responsibilities). They are ambiguous or uncertain enough, in terms of whether they are unfair or not, for people not to feel too much offended and for legitimacy to have a room to operate. In contrast, the condition of high disadvantage is obvious as to whether the authority's actions are unfair or not. There is no doubt that people are confronted to unacceptable injustices that they cannot justify in any way.

Moreover, in line with the model in Study 3, one could argue that the conditions of low and high disadvantage mostly differ on how they challenge individuals' moral values. Low disadvantages are likely to be viewed as not violating important moral stances. Therefore, individuals are less inclined to feel that they need to be redressed, especially when stemming from a legitimate authority. But when outcomes distribution is highly disadvantageous to the group, the legitimacy of the authority is overshadowed and loses its attenuating influence. In this condition, emotional and behavioural responses are shaped primarily by the moral values of individuals and not by the authority to which they no longer feel obliged to abide by the sole virtue of its legitimacy. In response to strong collective disadvantages, moral convictions take precedence over authority legitimacy in individuals' motivation to protest. Consistent with previous studies (e.g. Skitka, 2002; Skitka et al., 2009), this tends to corroborate the notion that the deference to legitimate authorities, as well as the restraint that they impose on the desire to revolt, is confined to situations where moral convictions do not come into play. From the perspective of social change, this indicates that the fight against injustices among those in subordinate positions is possible, provided that their sense of morality may be on the alert and their moral values be infringed. Moral convictions serve as a guide for making a decision as to whether participation in collective actions and disobedience to authority are acceptable or should be repressed. When disadvantages are high, the perceived damage to one's moral values signals that protesting is required, leaving legitimization processes unable to operate. While legitimacy constrains the desire to protest, since obligating to compliance through fear of informal sanctions by peers 
and formal sanctions by higher authorities, the violation of moral values frees individuals from such feelings of obligation and allows them to express their willingness to protest without restraint.

An alternative interpretation of our findings may be that the authority might no longer be perceived as legitimate in the condition of high disadvantage. Acting very unfairly would lead to a loss in legitimacy, thereby accounting for lower engagement in collective actions. To rule out this interpretation, we additionally tested whether the disadvantage manipulation might have an impact on perceived legitimacy. However, there was no statistical difference in legitimacy between the disadvantage conditions (Study 2: $F(1,226)=0.035, p=0.852$; Study 3: $F(2,299)=0.278$, $p=0.757$ ). Furthermore, we found that the differences between the low and high legitimacy conditions were roughly equivalent, regardless of disadvantage levels (Study 2: mean difference in the low disadvantage condition $=4.24 ; p<0.001$; mean difference in the high disadvantage condition $=3$. 37; $p<0.001$; Study 3: mean difference in the no disadvantage condition $=3.58 ; p<0.001$; mean difference in the low disadvantage condition $=3.22 ; p<0.001$; and mean difference in the high disadvantage condition $=2.67 ; p<0.001)$. Overall, these results indicate that participants were able to discriminate different levels of legitimacy even though disadvantages were strong. Therefore, we believe that the interpretation of our results in terms of an attenuating effect of legitimacy remains of relevance and best describes our findings. In the high disadvantage condition, the legitimacy of the authority did no longer serve as a buffer against engagement in protest although individuals kept on perceiving the authority figure as legitimate.

Moreover, our findings make an important contribution to social psychological research on collective actions. First, our research underscored the importance of authorities' role in studying the psychological antecedents of collective actions. As daily news regularly makes the case (e.g. demonstrations against political leaders), authority figures do indeed have a large share of responsibility in their emergence and development. They can be trigger elements, as in the case of movements aimed at condemning the negligence or inefficiency of public authorities in managing a social issue, and also decisive sources of regulation, depending on whether procedures for negotiation with third parties (e.g. trade unions) or, conversely, the use of public forces (e.g. police) have been implemented. Therefore, since protest actions can hardly be abstracted from a broader political context involving different categories of potentially antagonistic sources of power, it seems essential to further reflect on the role of political actors and especially of authority figures in our understanding of individual tendencies to engage collectively (see, for example, Osborne et al., 2019). This will undoubtedly pave the way for stimulating avenues of research that could complement or challenge the state of current knowledge. Second, our findings add to the literature by reconsidering the well-documented relationship between perceived disadvantage and engagement in collective actions (Klandermans, 1997; Wright, 2001). Protest activities may not be necessarily at work as individuals experience group-based deprivations. Legitimacy of authority does matter a lot in this respect. As a result, perceived injustice should not be analysed separately from legitimacy as both predict collective actions in concert. Injustice and legitimacy always articulate one with the other and can simultaneously eliminate the effects 
of the other as a function of their potential perceived strength. This way, our work goes way beyond the well-documented research showing that injustice is a key precursor to collective actions, and we argue that inclusion of legitimacy over injustice perceptions can considerably augment our understanding of collective actions. Therefore, we strongly urge researchers to further explore this line of research and integrate authority legitimacy as a key construct into the predictions of collective action models.

Third, by illuminating the importance of moral concerns in collective actions, our research programme fits consistently with the findings of a growing body of previous research (e.g. Kutlaca et al., 2019; Mazzoni et al., 2015; Van Zomeren et al., 2011, 2012, 2018). Likewise, we found that moral value violation constitutes a key energizer of engagement in collective actions. However, we provided new pieces of evidence showing how moral violation is related to disadvantages and authority legitimacy. While previous research did not tell much on how morality and injustice are both associated on collective action tendencies, we have shown here that very acute disadvantages may strongly lead individuals to collective actions precisely because they break with individuals' important moral stances. In this case, moral violation has such a potential that the legitimation processes are, to a certain extent, deactivated. In contrast, when moral values are not infringed by the collective disadvantages, engagement in collective actions crucially depends on whether the authority figure benefits from high or low legitimacy.

\section{Limitations}

Despite these important theoretical implications, our research contains some limitations. One pertains to the employment of vignettes. The main problem in using vignettes as a research methodology is that their ecological validity is relatively low and hardly allows to generalize the findings to real-life collective actions. The artificiality of such a research design may not reflect natural or genuine responses. Vignettes produce reactions that individuals imagine they would have experienced and not reactions that they would have really had in real-life situations, especially in the view of issues and constraints related to the workplace (e.g. fear of dismissal, labour market instability). Although Study 3 recruited only participants who were potentially familiar with the context described in the vignettes, it remains quite uncertain whether they correctly imagined themselves in the situation described, or whether they all imagined exactly the same situations based on their own experiences. In future studies, our findings should be replicated in real-life protest settings in which participants are likely to be personally sensitive to the conditions of low and high disadvantage. For example, one might consider asking people about how they would support and be willing to participate in ongoing or forthcoming social movements (e.g. anti-austerity movements) and how this may be predicted by perceptions of perceived disadvantage (e.g. perceptions of income inequality between the elite and the majority of the population) and legitimacy of authority (e.g. government or public authorities). Against this backdrop, another potential issue is that the vignettes described a workplace environment. Therefore, it is plausible that our 
findings are strongly context dependent and cannot be easily transferable to political contexts. Future research should be conducted in various contexts to offer greater validity and generalization to the current findings. Furthermore, although intentions to protest have been shown to predict protest behaviours (de Weerd \& Klandermans, 1999), our studies did not include direct measures of behaviour and cannot conclude on how disadvantage and legitimacy interact on actual participation in collective actions. Once more, conducting field studies might be a way to address this pitfall.

\section{Conclusion}

Our studies have underscored the importance of the role of authorities in engaging individuals in collective actions. We have shown that an authority figure with strong legitimacy is likely to temper anger and desire to revolt in the face of disadvantage, to the extent it does not place individuals' moral value system under threat. In this very case, the authority can no longer rely on legitimacy and will have to identify other means to contain possible uprisings and make people accommodate with an unfavourable situation. This reveals that group disadvantages, especially when they are not excessive and provoked by an authority who has gained strong legitimacy, may not necessarily lead to an intensive participation in protest actions. This may explain why, while socio-economic inequalities are still on the rise around the world (Piketty \& Saez, 2014), the number of collective actions does not increase proportionally and remains paradoxically low among those who are the first to suffer (Jost et al., 2017). Based on our results, we can conclude that the belief in the legitimacy of political institutions or governance structures, which contributes to the legitimization of injustices, paralyses at the same time the possibility of attributing legitimacy to collective organizations and movements aimed at redressing social equity.

Supplementary Information The online version contains supplementary material available at https://doi. org/10.1007/s11211-021-00374-z.

Funding Open Access funding provided by Université de Genève.

Data Availability All data concerning this research are openly available at https://osf.io/ar6vj/.

\section{Declarations}

Conflict of interest We do not have any conflicts of interest to declare.

Open Access This article is licensed under a Creative Commons Attribution 4.0 International License, which permits use, sharing, adaptation, distribution and reproduction in any medium or format, as long as you give appropriate credit to the original author(s) and the source, provide a link to the Creative Commons licence, and indicate if changes were made. The images or other third party material in this article are included in the article's Creative Commons licence, unless indicated otherwise in a credit line to the material. If material is not included in the article's Creative Commons licence and your intended use is not permitted by statutory regulation or exceeds the permitted use, you will need to obtain permission directly from the copyright holder. To view a copy of this licence, visit http://creativecommons.org/licen ses/by/4.0/. 


\section{References}

Abelson, R. P., \& Prentice, D. A. (1997). Contrast tests of interaction hypothesis. Psychological Methods, 2(4), 315-328. https://doi.org/10.1037/1082-989X.2.4.315

Ancelovici, M., Dufour, P., \& Nez, H. (2016). Street politics in the age of austerity: From the indignados to occupy. Amsterdam University Press.

Becker, J. C., Kraus, M. W., \& Rheinschmidt-Same, M. (2017). Cultural expressions of social class and their implications for group-related beliefs and behaviors. Journal of Social Issues, 73(1), 158-174. https://doi.org/10.1111/josi.12209

Becker, J. C., \& Tausch, N. (2015). A dynamic model of engagement in normative and non-normative collective action: Psychological antecedents, consequences, and barriers. European Review of Social Psychology, 26(1), 43-92. https://doi.org/10.1080/10463283.2015.1094265

Blader, S. L., \& Tyler, T. R. (2003). A four-component model of procedural justice: Defining the meaning of a "fair" process. Personality and Social Psychology Bulletin, 29(6), 747-758. https://doi.org/10. $1177 / 0146167203252811$

Caldeira, G. A., \& Gibson, J. L. (1992). The etiology of public support for the supreme court. American Journal of Political Science, 36(3), 635-664. https://doi.org/10.2307/2111585

Cohen, R. L. (1986). Power and justice in intergroup relations. In H. W. Bierhoff, R. L. Cohen, \& J. Greenberg (Eds.), Justice in social relations (pp. 65-84). Plenum.

Colquitt, J. A., Conlon, D., Wesson, M., Porter, C. O. L., \& Ng, K. L. (2001). Justice at the millennium: A meta-analytic review of 25 years of organizational justice. Journal of Applied Psychology, 86(3), 425-445. https://doi.org/10.1037/0021-9010.86.3.425

Colquitt, J. A., Greenberg, J., \& Zapata-Phelan, C. P. (2005). What is organizational justice? A historical overview. In J. Greenberg \& J. A. Colquitt (Eds.), Handbook of Organizational Justice (pp. 3-58). Erlbaum.

de Weerd, M., \& Klandermans, P. G. (1999). Group identification and social protest: Farmers' protest in the Netherlands. European Journal of Social Psychology, 29(8), 1073-1095.

Della Porta, D., \& Mattoni, A. (2014). Spreading protest: Social movements in times of crisis. Colchester: ECPR Press.

Faul, F., Erdfelder, E., Lang, A. G., \& Buchner, A. (2007). G*Power 3: A flexible statistical power analysis program for the social, behavioral, and biomedical sciences. Behavior Research Methods, 39(2), 175-191. https://doi.org/10.3758/BF03193146

Folger, R., \& Cropanzano, R. (1998). Organizational justice and human resource management. Sage.

Gibson, J. L. (1989). Understandings of justice: Institutional legitimacy, procedural justice, and political tolerance. Law \& Society Review, 23(3), 469-496. https://doi.org/10.2307/3053830

Haidt, J., Koller, S. H., \& Dias, M. G. (1993). Affect, culture, and morality, or is it wrong to eat your dog? Journal of Personality and Social Psychology, 65(4), 613-628. https://doi.org/10.1037//0022-3514. 65.4 .613

Hayes, A. F. (2013). Introduction to mediation, moderation, and conditional process analysis: A regression-based approach. Guilford Press.

Hays, N. A., \& Goldstein, N. J. (2015). Power and legitimacy influence conformity. Journal of Experimental Social Psychology, 60, 17-26. https://doi.org/10.1016/j.jesp.2015.04.010

Hegtvedt, K. A., Clay-Werner, J., \& Johnson, C. (2003). The social context of responses to injustice: Considering the indirect and direct effects of group-level factors. Social Justice Research, 16(4), 343-366. https://doi.org/10.1023/A:1026309615276

Hegtvedt, K. A., \& Johnson, C. (2000). Justice beyond the individual: A future with legitimation. Social Psychology Quarterly, 63(4), 298-311. https://doi.org/10.2307/2695841

Hegtvedt, K. A., \& Johnson, C. (2009). Power and justice: Toward an understanding of legitimacy. American Behavioral Scientist, 53(3), 376-399. https://doi.org/10.1177/0002764209338798

Hegtvedt, K. A., Johnson, C., \& Watson, L. (2016). Social dynamics of legitimacy and justice. In C. Sabbagh \& M. Schmitt (Eds.), Handbook of social justice theory and research (pp. 425-444). Springer.

Jackson, J., Bradford, B., Hough, M., Myhill, A., Quinton, P. K., \& Tyler, T. R. (2012). Why do people comply with the law? Legitimacy and the influence of legal institutions. The British Journal of Criminology, 52(6), 1051-1071. https://doi.org/10.1093/bjc/azs032

Johnson, C., Dowd, T. J., \& Ridgeway, C. L. (2006). Legitimacy as a social process. Annual Review of Sociology, 32, 53-78. https://doi.org/10.1146/annurev.soc.32.061604.123101 
Johnson, C., \& Ford, R. (1996). Dependence, power, legitimacy, and tactical choice. Social Psychology Quarterly, 59(2), 126-139. https://doi.org/10.2307/2787047

Johnson, C., Ford, R., \& Kaufman, J. M. (2000). Emotional reactions to conflict: Do dependence and legitimacy matter? Social Forces, 79(1), 107-137. https://doi.org/10.2307/2675566

Johnson, C., Hegtvedt, K. A., Khanna, N., \& Scheuerman, H. L. (2016). Legitimacy processes and emotional responses to injustice. Social Psychology Quaterly, 79(2), 95-114. https://doi.org/10.1177/ 0190272516645317

Jost, J. T., Becker, J., Osborne, D., \& Badaan, V. (2017). Missing in (collective) action: Ideology, system justification, and the motivational antecedents of two types of protest behavior. Current Directions in Psychological Science, 26(2), 99-108. https://doi.org/10.1177/0963721417690633

Jost, J. T., Chaikalis-Petritsis, V., Abrams, D., Sidanius, J., Van Der Toorn, J., \& Bratt, C. (2012). Why men (and women) do and don't rebel effects of system justification on willingness to protest. Personality and Social Psychology Bulletin, 38(2), 197-208. https://doi.org/10.1177/01461 67211422544

Kelman, H. C., \& Hamilton, V. L. (1989). Crimes of obedience: Toward a social psychology of authority and responsibility. Yale University Press.

Klandermans, B. (1997). The social psychology of protest. Blackwell Publishers.

Kutlaca, M., Van Zomeren, M., \& Epstude, K. (2019). Our right to a steady ground: Perceived rights violations motivate collective action against human-caused earthquakes. Environment and Behavior, 51(3), 315-344. https://doi.org/10.1177/0013916517747658

Leach, C. W., Iyer, A., \& Pedersen, A. (2007). Angry opposition to government redress: When the structurally advantaged perceive themselves as relatively deprived. British Journal of Social Psychology, 46(1), 191-204. https://doi.org/10.1348/014466606X99360

Levi, M., Sacks, A., \& Tyler, T. R. (2009). Conceptualizing legitimacy, measuring legitimating beliefs. American Behavioral Scientist, 53(3), 354-375. https://doi.org/10.1177/0002764209 338797

Mackie, D. M., Devos, T., \& Smith, E. R. (2000). Intergroup emotions: Explaining offensive action tendencies in an intergroup context. Journal of Personality and Social Psychology, 79(4), 602-616. https://doi.org/10.1037/0022-3514.79.4.602

Mazzoni, D., Van Zomeren, M., \& Cicognani, E. (2015). The motivating role of perceived right violation and efficacy beliefs in identification with the Italian water movement. Political Psychology, 36(3), 315-330. https://doi.org/10.1111/pops.12101

Milgram, S. (1974). Obedience to authority: An experimental view. Harper \& Row.

Molho, C., Tybur, J. M., Güler, E., Balliet, D. P., \& Hofmann, W. (2017). Disgust and anger relate to different aggressive responses to moral violations. Psychological Science, 28(5), 609-619. https://doi. org/10.1177/0956797617692000

Mullen, E., \& Nadler, J. (2008). Moral spillovers: The effect of moral violations on deviant behavior. Journal of Experimental Social Psychology, 44(5), 1239-1245. https://doi.org/10.2139/ssrn.11204 44

Mullen, E., \& Skitka, L. J. (2006). Exploring the psychological underpinnings of the moral mandate effect: Motivated reasoning, identification, or affect? Journal of Personality and Social Psychology, 90(4), 629-643. https://doi.org/10.1037/0022-3514.90.4.629

Murphy, K., Tyler, T. R., \& Curtis, A. (2009). Nurturing regulatory compliance: Is procedural justice effective when people question the legitimacy of the law? Regulation and Governance, 3(1), 1-26. https://doi.org/10.1111/j.1748-5991.2009.01043.x

Occupy Wall Street. (2011). Declaration of the occupation of New York City. Zucotti Park, NY.

Osborne, D., Jost, J. T., Becker, J. C., Badaan, V., \& Sibley, C. G. (2019). Protesting to challenge or defend the system? A system justification perspective on collective action. European Journal of Social Psychology, 49(2), 244-269. https://doi.org/10.1002/ejsp.2522

Piketty, T., \& Saez, E. (2014). Inequality in the long run. Science, 344, 838-843.

Runciman, W. G. (1966). Relative deprivation and social justice: A study of attitudes to social inequality in twentieth-century England. University of California Press.

Skitka, L. J., Bauman, C. W., \& Mullen, E. (2008). Morality and justice: An expanded theoretical perspective and review. In K. A. Hedgvedt \& J. Clay-Warner (Eds.), Advances in Group Processes, Vol. 25 (pp. 1-27). Bingley: Emerald Group Publishing Limited.

Skitka, L. J. (2002). Do the means always justify the ends, or do the ends sometimes justify the means? A value protection model of justice reasoning. Personality and Social Psychology Bulletin, 28(5), 588-597. https://doi.org/10.1177/0146167202288003 
Skitka, L. J., Bauman, C. W., \& Lytle, B. L. (2009). Limits on legitimacy: Moral and religious convictions as constraints on deference to authority. Journal of Personality and Social Psychology, 97(4), 567-578. https://doi.org/10.1037/a0015998

Skitka, L. J., \& Morgan, G. S. (2014). The social and political implications of moral conviction. Political Psychology, 35(1), 95-110. https://doi.org/10.1111/pops.12166

Skitka, L. J., \& Mullen, E. (2002). Understanding judgments of fairness in a real-world political context: A test of the value protection model of justice reasoning. Personality and Social Psychology Bulletin, 28(10), 1419-1429. https://doi.org/10.1177/014616702236873

Smith, H. J., \& Ortiz, D. (2002). Is it just me? The different consequences of personal and group relative deprivation. In I. Walker \& H. J. Smith (Eds.), relative deprivation (pp. 91-118). Cambridge University Press.

Sunshine, J., \& Tyler, T. R. (2003). The role of procedural justice and legitimacy in shaping public support for policing. Law and Society Review, 37(3), 513-548. https://doi.org/10.1111/15405893.37030 02

Tausch, N., Becker, J. C., Spears, R., Christ, O., Saab, R., Singh, P., \& Siddiqui, R. N. (2011). Explaining radical group behaviour: Developing emotion and efficacy routes to normative and non-normative collective action. Journal of Personality and Social Psychology, 101(1), 129-148. https://doi.org/ $10.1037 / \mathrm{a} 0022728$

Teixeira, C. P., Spears, R., \& Yzerbyt, V. (2020). Is Martin Luther King or Malcolm X the more acceptable face of protest? High-status groups' reactions to low-status groups' collective action. Journal of Personality and Social Psychology. https://doi.org/10.1037/pspi0000195

Tetlock, P. E., Kirstel, O. V., Elson, S. B., Green, M. C., \& Lerner, J. S. (2000). The psychology of the unthinkable: Taboo trade-offs, forbidden base rates, and heretic counterfactuals. Journal of Personality and Social Psychology, 78(5), 853-870. https://doi.org/10.1037//0022-3514.78.5.853

Thomas, E. F., \& McGarty, C. (2009). The role of efficacy and moral outrage norms in creating the potential for international development activism through group-based interaction. British Journal of Social Psychology, 48(1), 115-134. https://doi.org/10.1348/014466608X313774

Thomas, E. F., McGarty, C., \& Mavor, K. I. (2009). Aligning identities, emotions, and beliefs to create commitment to sustainable social and political action. Personality and Social Psychology Review, 13(3), 194-218. https://doi.org/10.1177/1088868309341563

Tyler, T. R. (2010). Legitimacy and rule adherence: A psychological perspective on the antecedents and consequences of legitimacy. In D. R. Bobocel, A. C. Kay, M. P. Zanna, \& J. M. Olson (Eds.), The psychology of justice and legitimacy (pp. 251-271). New York, NY: Psychology Press.

Tyler, T. R. (1997). The psychology of legitimacy: A relational perspective on voluntary deference to authorities. Personality and Social Psychology Review, 1(4), 323-345. https://doi.org/10.1207/ s15327957pspr0104_4

Tyler, T. R. (2006a). Psychological perspectives on legitimacy and legitimation. Annual Review of Psychology, 57(1), 375-400. https://doi.org/10.1146/annurev.psych.57.102904.190038

Tyler, T. R. (2006b). Why people obey the law. Princeton University Press.

Tyler, T. R., \& Huo, Y. J. (2002). Trust in the law: Encouraging public cooperation with the police and courts. Russell Sage Foundation.

Tyler, T. R., \& Lind, E. A. (1992). A relational model of authority in groups. In M. Zanna (Ed.), Advances in experimental social psychology (pp. 115-191). Academic Press.

Van Stekelenburg, J., \& Klandermans, B. (2013). The social psychology of protest. Current Sociology, 61(5-6), 886-905. https://doi.org/10.1177/0011392113479314

Van Zomeren, M., Kutlaca, M., \& Turner-Zwinkels, F. (2018). Integrating who "we" are with what "we" (will not) stand for: A further extension of the Social Identity Model of Collective Action. European Review of Social Psychology, 29(1), 122-160. https://doi.org/10.1080/10463283.2018.1479347

Van Zomeren, M., \& Lodewijkx, H. F. M. (2005). Motivated responses to 'senseless' violence: Explaining emotional and behavioural responses through person and position identification. European Journal of Social Psychology, 35(6), 755-766. https://doi.org/10.1002/ejsp.274

Van Zomeren, M., Postmes, T., \& Spears, R. (2008). Toward an integrative social identity model of collective action: A quantitative research synthesis of three sociopsychological perspectives. Psychological Bulletin, 134(4), 504-535. https://doi.org/10.1037/0033-2909.134.4.504

Van Zomeren, M., Postmes, T., \& Spears, R. (2012). On conviction's collective consequences: Integrating moral conviction with the social identity model of collective action. British Journal of Social Psychology, 51(1), 52-71. https://doi.org/10.1111/j.2044-8309.2010.02000.x 
Van Zomeren, M., Postmes, T., Spears, R., \& Bettache, K. (2011). Can moral convictions motivate the advantaged to challenge social inequality? Extending the social identity model of collective action. Group Processes \& Intergroup Relations, 14(5), 735-753. https://doi.org/10.1177/1368430210 395637

Van Zomeren, M., Spears, R., Fischer, A. H., \& Leach, C. W. (2004). Put your money where your mouth is! Explaining collective action tendencies through group-based anger and group efficacy. Journal of Personality and Social Psychology, 87(5), 649-664. https://doi.org/10.1037/0022-3514.87.5.649

van den Bos, K., Lind, E. A., \& Wilke, H. A. M. (2001). The psychology of procedural and distributive justice viewed from the perspective of fairness heuristic theory. In R. Cropanzano (Ed.), Series in applied psychology. Justice in the workplace: From theory to practice (pp. 49-66). Mahwah, NJ: Lawrence Erlbaum Associates Publishers.

Walker, H. A. (2014). Legitimacy and inequality. In J. McLeod, E. Lawler, \& M. Schwalbe (Eds.), Handbook of the social psychology of inequality (pp. 353-377). Springer.

Walker, H. A., Thomas, G. M., \& Zelditch, M. (1986). Legitimation, endorsement, and stability. Social Forces, 64(3), 620-643. https://doi.org/10.2307/2578816

Walker, I., \& Smith, H. J. (2002). Relative deprivation: Specification, development, and integration. Cambridge University Press.

Wright, S. C. (2001). Strategic collective action: Social psychology and social change. In R. Brown \& S. Gaertner (Eds.), Intergroup processes: Blackwell handbook of social psychology (Vol. 4, pp. 409430). Blackwell Press.

Wright, S. C. (2010). Collective action and social change. In J. F. Dovidio, M. Hewstone, P. Glick, \& V. M. Esses, (Eds.), The SAGE Handbook of Prejudice, Stereotyping and Discrimination (pp. 577-596). SAGE Publications Ltd.

Wright, S. C., Taylor, D. M., \& Moghaddam, F. M. (1990). Responding to membership in a disadvantaged group: From acceptance to collective protest. Journal of Personality and Social Psychology, 58(6), 994-1003. https://doi.org/10.1037//0022-3514.58.6994

Yzerbyt, V., Dumont, M., Wigboldus, D., \& Gordijn, E. (2003). I feel for us: The impact of categorization and identification on emotions and action tendencies. British Journal of Social Psychology, 42(4), 533-549. https://doi.org/10.1348/014466603322595266

Zelditch, M. (2001). Theories of legitimacy. In J. T. Jost \& B. Major (Eds.), The psychology of legitimacy: Emerging perspectives on ideology, justice, and intergroup relations (pp. 33-53). Cambridge University Press.

Zelditch, M., \& Walker, H. A. (1984). Legitimacy and the stability of authority. In E. J. Lawler (Ed.), Advances in group processes: Theory and research (pp. 1-25). JAI Press.

Zelditch, M., \& Walker, H. A. (2003). The legitimacy of regimes. In S. R. Thye \& J. Skvoretz (Eds.), Power and status (pp. 217-249). Emerald Group Publishing.

Publisher's Note Springer Nature remains neutral with regard to jurisdictional claims in published maps and institutional affiliations. 